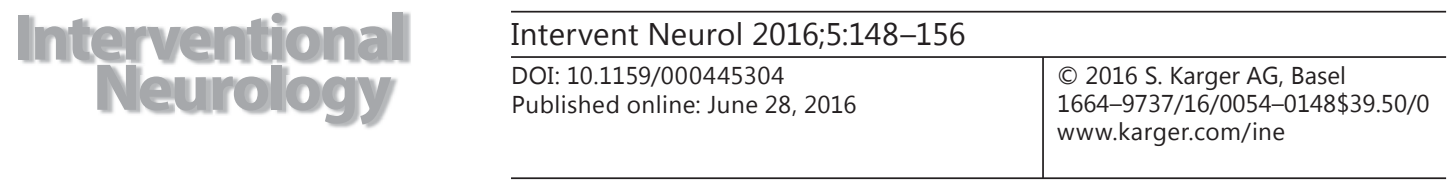

\title{
Review
}

\section{Treatment Strategies for Acute Ischemic Stroke Caused by Carotid Artery Occlusion}

\author{
Wei Li Qin Yin Gelin Xu Xinfeng Liu \\ Department of Neurology, Jinling Hospital, Southern Medical University, Nanjing, China
}

\section{Key Words}

Acute ischemic stroke $\cdot$ Intravenous thrombolysis · Intra-arterial therapy · Carotid artery occlusion

\begin{abstract}
Background: Acute ischemic stroke caused by internal carotid artery (ICA) occlusion usually has a poor prognosis, especially the T occlusion cases without functional collaterals. The efficacy of intravenous (IV) or intra-arterial (IA) thrombolysis with recombinant tissue plasminogen activator (rt-PA) remains ambiguous in these patients. Eendovascular recanalization of the occluded carotid has been attempted in recent years as a potential strategy. However, the different etiologies of ICA occlusion pose a significant challenge to neurointerventionists. Recently, several endovascular evolvements have been reported in treating carotid occlusionrelated stroke. This review summarizes the current status of treatment for acute ICA occlusion.
\end{abstract}

(C) 2016 S. Karger AG, Basel

\section{Introduction}

Acute ischemic stroke (AIS) is a complex disease, incorporating several subtypes with different underlying pathologies. Acute internal carotid artery (ICA) occlusion is one of the most devastating occasions, which represents $6-15 \%$ in AIS patients [1]. Patients usually bear high National Institutes of Health Stroke Scale (NIHSS) scores because of severe neurological deficits, with only $2-12 \%$ achieving good recovery, $40-69 \%$ having a severe deficit, and $16-55 \%$ dying from AIS [2]. Recanalization rates after intravenous (IV) and intra-arterial (IA) therapy range from 4.4 to 12.5 and from 62 to $63 \%$, respectively. A huge clot burden and 
Li et al.: Treatment Strategies for Acute Ischemic Stroke Caused by Carotid Artery Occlusion

Table 1. Studies of intravenous thrombolytic therapy in acute ischemic stroke with ICA occlusion

\begin{tabular}{|c|c|c|c|c|c|c|}
\hline Study & Treatment & $\begin{array}{l}\text { Patients, } \\
\mathrm{n}\end{array}$ & $\begin{array}{l}\text { Favorable outcome, } \\
\text { definition }\end{array}$ & $\begin{array}{l}\text { Favorable } \\
\text { outcome, n (\%) }\end{array}$ & $\begin{array}{l}\text { Mortality, } \\
\text { n (\%) }\end{array}$ & $\begin{array}{l}\text { sICH, } \\
\text { n (\%) }\end{array}$ \\
\hline ICARO [17], 2012 & IV tPA within $4.5 \mathrm{~h}$ & 253 & mRS $0-2$ at 3 mo. & 73 (29) & $65(26)$ & $12(5)$ \\
\hline ICARO-3 [26], 2015 & IV tPA within $4.5 \mathrm{~h}$ & 324 & mRS $0-2$ at 3 mo. & $89(27.4)$ & $75(23.1)$ & n.a. \\
\hline EPITHET [16], 2010 & IV tPA within $6 \mathrm{~h}$ & 13 & mRS $0-2$ at 3 mo. & $0(0)$ & n.a. & n.a. \\
\hline CLOTBUST [22], 2007 & IV tPA within $3 \mathrm{~h}$ & 25 & mRS $0-2$ at 3 mo. & $5(20)$ & 7 (28) & 3 (12) \\
\hline
\end{tabular}

limited delivery of recombinant tissue plasminogen activator (rt-PA) to the intracranial occlusion may explain the poor prognosis $[3,4]$. Recently, five published randomized clinical trials have demonstrated the safety and effectiveness of endovascular treatment for anterior intracranial proximal artery occlusion, and the proportion of patients with acute ICA occlusion accounted for up to $20 \%$ of the patients in these trials [5-9].

Although there is no randomized controlled trial comparing endovascular treatment with medical therapy in patients with acute ICA occlusion, successful revascularization of acute ICA occlusion by endovascular treatment and acceptable clinical outcome were reported by a number of case series [10-12]. Several endovascular approaches have been described in current literatures, including IA thrombolysis (IAT), microwire clot disruption, angioplasty, thromboaspiration, stenting and thrombectomy with stent retrievers [13]. One systematic review suggests that the mechanical treatment, particularly emergency stenting in extracranial occlusions, results in better recanalization, higher favorable outcome rates and lower death rates than IAT in patients with acute ICA occlusion [14].

\section{Thrombolysis}

After several carefully designed randomized controlled trials, IV rt-PA has been established as the first-line treatment for AIS, and an increasing number of cases were treated by rt-PA around the world. However, the reported recanalization rates were unsatisfactorily low (only 10-15\%) after IV thrombolysis in the setting of acute ICA occlusion even among patients having been treated within $3 \mathrm{~h}$ of stroke onset [15]. Previous studies reported their results of patients with acute ICA occlusion as detailed below. The Echoplanar Imaging Thrombolytic Evaluation Trial (EPITHET; table 1) was the only randomized trial comparing the effect of IV rt-PA with placebo 3-6 h after onset using serial echoplanar magnetic resonance (MR) imaging. Patients with ICA obstruction did not achieve good clinical outcome [modified Rankin Scale (mRS) score, 0-2 at 3 months; rt-PA 0\% vs. placebo 23\%; p = 0.257]. However, the IV rt-PA group had much worse outcomes compared to the placebo group [mRS score 5-6; rt-PA88 vs. 38\%; adjusted odds ratio (OR), 11.2; 95\% confidence interval (CI), 1.1-120.4; $\mathrm{p}=$ 0.04]. However, the relatively small sample size (only 22 patients with ICA occlusion) may not reflect practice and outcomes in the real world [16]. The Internal Carotid ARtery Occlusion study (ICARO) was a case-control multicenter study including 253 cases and 253 controls [17] (table 1). Patients with acute ICA occlusion treated with IV rt-PA within $4.5 \mathrm{~h}$ from symptom onset (cases) were compared to the group (controls) not treated with rt-PA because symptom onset was either between 4.5 and $12 \mathrm{~h}$, earlier or uncertain. The favorable outcome (mRS score 0-2) was higher in cases (28.9\%) than in controls $(20.6 \%)$, but an increase in mortality ( 25.7 vs. $15.4 \%, \mathrm{p}=0.001$ ) and intracranial bleeding ( 2.8 vs. $0.4 \%, \mathrm{p}=0.068$ ) was the trade-off for this benefit. 
The increased death rates associated with thrombolytic treatment have been attributed to several factors. First, patients with ICA occlusion generally have a large infarcted territory surrounded by a large edema, which may deteriorate by thrombolytic treatment. Second, edema formation and enlarged developing infarcts may be exacerbated by force reperfusion of the irreversibly damaged tissue.

Meanwhile, the ICARO-2 study [18], for which data were collected in the SITS-ISTR, found that mortality was 2 -fold higher in patients with extracranial ICA (eICA) occlusion compared to patients without eICA occlusion, even when both of them were treated with IV rt-PA within $4.5 \mathrm{~h}$ (table 1). Furthermore, more than $70 \%$ of the patients with carotid occlusion had a mRS score $>3$ at 90 days. The higher mortality seems to be due to the intrinsic pathophysiology of carotid occlusion because patients with eICA occlusion had a more severe stroke compared to patients without eICA occlusion (mean NIHSS score of 15 on admission compared to 12).

Several factors may influence the outcomes of IV rt-PA treatment among patients with ICA occlusion. First, experimental studies have shown that effective delivery and distribution of thrombotic drug into the clot may accelerate fibrinolysis because the fibrinolysis rate depends on the pressure gradient to which the clot is exposed [19]. Acute ICA occlusion leads to a regional decrease in cerebral perfusion pressure, which may not only hamper middle cerebral artery (MCA) clot dissolution but also cause hemodynamic instability, increasing the probability of rethrombosis after incomplete recanalization [20]. Second, in acute ICA occlusion of the tandem distal occlusion type, the presence of an ipsilateral MCA occlusion is generally caused by artery-to-artery embolism, with a platelet-rich, lytic-resistant clot proceeding from the carotid plaque. Platelet-rich clots have been shown to have a poorer propensity for lysis with rt-PA compared to fibrin-rich clots [21]. Third, because of the high clot burden and poor collateral circulation, functional ICA-T [extra- and/or intracranial occlusion of the ICA extended into both the anterior cerebral artery (ACA) A1 and MCA M1] occlusions show poor response to IV thrombolysis [22]. These data suggest that patients with ICA obstruction may be potential candidates for trials using other reperfusion strategies, such as IAT or thrombectomy assisted by carotid stenting.

\section{IA Therapy}

With the advancement in stent retrievers, the recanalization rates in patients with ICA occlusion are increasing. It is foreseeable that endovascular therapy will be recommended in future guidelines $[23,24]$. However, the proportion of patients with acute carotid occlusion concurs between 13 and $44.1 \%$ in five positive randomized controlled trials [5-9]. Up to date, multiple nonrandomized case series reported different results with regard to outcomes and complication in IA therapy for acute ICA occlusion [10-12]. In 2002, Zaidat et al. [4] reported a small case series of 18 patients with acute occlusion of the distal ICA ('T' occlusion) who presented within $6 \mathrm{~h}$ after symptom onset and were treated by IA or IV/IA therapy. Complete recanalization ( 62 vs. $80.0 \%, \mathrm{p}=$ n.s.) and favorable outcome (mRS score $0-1$ ) at 3 months (15.4 vs. $40.0 \%, \mathrm{p}=$ n.s.) did not reach significant difference between the two groups. However, the total mortality rate was $50 \%$ higher in the whole group $(9 / 18$; including IA and IV/IA therapy), even half of the patients.

ICARO-3 was also a case-control multicenter study including 324 cases and 324 controls [25] (table 1). Patients with acute ICA occlusion treated with endovascular treatment within $6 \mathrm{~h}$ from symptom onset (cases) were compared to the group treated with IV rt-PA within $4.5 \mathrm{~h}$ (controls). Hundred and five cases $(32.4 \%)$ had a good outcome (mRS score $0-2$ ) as compared to 89 controls (27.4\%; OR 1.25, 95\% CI 0.88-1.79, $\mathrm{p}=0.1$ ). The rates of patients with severe disability or death (mRS score 5-6) were similar in cases and controls (30.5 vs. 
$32.4 \%, \mathrm{p}=0.67$ ). ICARO-3 failed to show the superiority of endovascular treatment in acute ICA occlusion compared to IV rt-PA treatment. However, an interesting additional analysis found a potential benefit of IA treatment alone compared to IV rt-PA (mRS score 0-2, 35.3 vs. $27.4 \%$, OR $1.75,95 \%$ CI $1.00-3.03, \mathrm{p}=0.05$ ) when excluding the patients treated with bridge therapy (combination of IV thrombolysis and IA procedures). The main limitation of this large study was that the stroke-workflow efficiencies were lower than in the positive studies (MR CLEAN, EXTEND IA, ESCAPE, SWIFT PRIME and REVASCAT). The median treatment time from stroke onset to IV rt-PA was $154 \mathrm{~min}$, for the IA procedure it was 240 min and for the bridge therapy it was $155 \mathrm{~min}$. All of these were longer than those in the positive studies [5-9]. Second, outcomes with rapid reperfusion are limited by long procedure times. The solitaire flow restoration thrombectomy devices allow for rapid complete recanalization rates in the occlusion of the anterior intracranial proximal artery with better outcomes [26]. However, the ICARO-3 study did not investigate the effect of a specific device. The heterogeneity of the old techniques may change the outcomes of endovascular therapy. Third, noninvasive computed tomography (CT, only $34.9 \%$ ) or MR angiography $(14.5 \%)$ to confirm the status of a target vessel occlusion was not commonly used in the control group. The site of arterial occlusion predicts the response to IV thrombolysis for stroke [22]. Thus, the results of the ICARO-3 study are outdated and should be interpreted with caution in the modern era.

Half of all patients presenting with acute occlusion of the eICA may have comorbid MCA occlusion, as approximately $25 \%$ of the patients with MCA occlusion have concomitant ICA occlusion. This type of occlusion was defined as tandem occlusion. The natural history of this lesion often leads to high morbidity and mortality in $20 \%$ of the patients [27]. Dababneh et al. [28] were the first to describe the utilization of the combined approach of IV rt-PA followed by ICA balloon angioplasty and MCA mechanical thrombectomy in 2 cases (table 2). Successful recanalization and favorable outcome were achieved in both cases. Papanagiotou et al. [29] reported their experiences with emergency carotid stent placement and intracranial thrombectomy procedures in 22 case series and used both stent retriever devices (Solitaire) and aspiration catheter systems (Penumbra; table 2). Successful revascularization was achieved in 21 patients (95\%) with acute stent implantation in the eICA. The solitaire system achieved successful intracranial recanalization (100\%) in 9 intracranial tandem occlusion cases, and 4 of $9(44 \%)$ patients had favorable outcomes.

Kappelhof et al. [14] were the first to review the IA treatment of AIS due to ICA occlusion and the difference between IA treatment modalities and occlusion. Successful recanalization rates were achieved in 55\% of the patients with an intracranial ICA occlusion and in $71 \%$ of the patients with an occlusion of the eICA. Compared with IAT, carotid stenting and mechanical thrombectomy are associated with significantly higher recanalization rates and favorable outcome in patients with AIS due to an extracranial and/or intracranial ICA occlusion. A possible explanation could be that most extracranial occlusions were related to severe atherosclerotic stenosis or dissection; greater and faster flow restoration to improve distal perfusion and deliver endogenous fibrinolytics may have resulted from carotid stenting compared to IAT. Another explanation is that an occlusion of the intracranial ICA is often associated with a larger clot; successful recanalization is more likely to be achieved in mechanical thrombectomy than in IAT.

Recently, several case series reported the efficacy and safety of emergency ICA stent placement followed by anterior circulation thrombectomy [10-12, 30-32]. Despite the lack of direct comparative studies, the overall rate of successful reperfusion results [treatment in cerebral infarction (TICI) score $\geq 2 \mathrm{~b}$ ] ranged from 63 to $79 \%$ in these studies, which was similar to the rates reported in the recent stent-retriever trials in patients with isolated intracranial occlusions (modified TICI score $\geq 2 \mathrm{~b}$ of $72.4 \%$ in ESCAPE, $88 \%$ in SWIFT PRIME). 


\begin{tabular}{l|l}
\hline DOI: $10.1159 / 000445304$ & $\begin{array}{l}\text { C } 2016 \text { S. Karger AG, Basel } \\
\text { www.karger.com/ine }\end{array}$ \\
\hline $\begin{array}{l}\text { Li et al.: Treatment Strategies for Acute Ischemic Stroke Caused by Carotid Artery } \\
\text { Occlusion }\end{array}$
\end{tabular}

Table 2. Studies of IA therapy in acute ischemic stroke with ICA occlusion

\begin{tabular}{|c|c|c|c|c|c|c|c|c|}
\hline $\begin{array}{l}\text { First author [ref.], } \\
\text { year }\end{array}$ & Treatment & $\begin{array}{l}\mathrm{Pa}- \\
\text { tients, } \\
\mathrm{n}\end{array}$ & $\begin{array}{l}\text { Successful } \\
\text { recanalization, } \\
\text { definition }\end{array}$ & $\begin{array}{l}\text { Successful } \\
\text { recanalization, } \\
\text { n (\%) }\end{array}$ & $\begin{array}{l}\text { Favorable } \\
\text { outcome, } \\
\text { definition }\end{array}$ & $\begin{array}{l}\text { Favorable } \\
\text { outcome, } \\
\text { n (\%) }\end{array}$ & $\begin{array}{l}\text { Mortality, } \\
\mathrm{n}(\%)\end{array}$ & $\begin{array}{l}\text { sICH } \\
\mathrm{n}(\%)\end{array}$ \\
\hline $\begin{array}{l}\text { Cohen [11], } \\
2015\end{array}$ & $\begin{array}{l}\text { IV tPA, angioplasty, stent, stent } \\
\text { retriever }\end{array}$ & 24 & TIMI 3 & 19 (79) & mRS score $0-2$ at 3 mo. & $13(76)$ & $2(8)$ & $0(0)$ \\
\hline $\begin{array}{l}\text { Heck [30], } \\
2015\end{array}$ & $\begin{array}{l}\text { IV tPA, stent, mechanical } \\
\text { thrombectomy }\end{array}$ & 23 & TICI $2 \mathrm{~b} / 3$ & $17(74)$ & $\mathrm{mRS}$ score $0-2$ at $3 \mathrm{mo}$. & $12(52)$ & 9 (39) & $5(22)$ \\
\hline $\begin{array}{l}\text { Lockau [31], } \\
2015\end{array}$ & $\begin{array}{l}\text { IV tPA, angioplasty, stent, stent } \\
\text { retriever }\end{array}$ & 37 & TICI $2 \mathrm{~b} / 3$ & 27 (73) & mRS score $0-2$ at 3 mo. & $17(45.9)$ & 7 (18.9) & $4(10.8)$ \\
\hline $\begin{array}{l}\text { Puri [32], } \\
2015\end{array}$ & $\begin{array}{l}\text { IV tPA, angioplasty, stent, stent } \\
\text { retriever }\end{array}$ & 28 & TICI $2 \mathrm{~b} / 3$ & $20(71.4)$ & mRS score $0-2$ at 3 mo. & $11(39.3)$ & $4(14.3)$ & $2(7.1)$ \\
\hline $\begin{array}{l}\text { Lescher [34], } \\
2015\end{array}$ & $\begin{array}{l}\text { IV tPA, angioplasty, stent, stent } \\
\text { retriever }\end{array}$ & 39 & TICI $2 b / 3$ & $25(64)$ & mRS score $0-2$ at 3 mo. & $14(36)$ & $4(10)$ & $4(10)$ \\
\hline $\begin{array}{l}\text { Stampfl [12], } \\
2014\end{array}$ & $\begin{array}{l}\text { IV tPA, angioplasty, stent, stent } \\
\text { retriever }\end{array}$ & 24 & TICI $2 \mathrm{~b} / 3$ & $15(62.5)$ & mRS score $0-2$ at 3 mo. & 7 (29.2) & $4(16.6)$ & $4(16.6)$ \\
\hline $\begin{array}{l}\text { Paciaroni [25], } \\
2015\end{array}$ & $\begin{array}{l}\text { IA tPA or UK, stent, } \\
\text { mechanical, thrombectomy }\end{array}$ & 324 & TICI $2 / 3$ & $182(68.7)$ & mRS score $0-2$ at 3 mo. & $105(32.4)$ & $57(17.6)$ & n.a. \\
\hline $\begin{array}{l}\text { Woodward [36], } \\
2014\end{array}$ & $\begin{array}{l}\text { IV tPA, aspiration, stent } \\
\text { retriever }\end{array}$ & 7 & TICI $2 \mathrm{~b} / 3$ & $7(100)$ & mRS score $0-2$ at 3 mo. & $6(85.7)$ & $1(14.3)$ & $0(0)$ \\
\hline $\begin{array}{l}\text { Mpotsaris [10], } \\
2013\end{array}$ & $\begin{array}{l}\text { IV tPA, stenting, mechanical } \\
\text { thrombectomy }\end{array}$ & 41 & TIMI $2 / 3$ & $35(85)$ & mRS score $0-2$ at $3 \mathrm{mo}$. & 15 (37) & $15(37)$ & $3(7)$ \\
\hline $\begin{array}{l}\text { Fischer [33], } \\
2013\end{array}$ & $\begin{array}{l}\text { IV or IA tPA, angioplasty, } \\
\text { mechanical thrombectomy }\end{array}$ & 201 & TIMI 2/3 & $157(78)$ & mRS score $0-2$ at $3 \mathrm{mo}$. & $54(28)$ & $60(29.9)$ & $12(6)$ \\
\hline $\begin{array}{l}\text { Dababneh [28], } \\
2012\end{array}$ & $\begin{array}{l}\text { IV tPA, angioplasty, } \\
\text { mechanical thrombectomy }\end{array}$ & 2 & TICI $2 / 3$ & $2(100)$ & mRS score $0-2$ at 2 mo. & $2(100)$ & $0(0)$ & $0(0)$ \\
\hline $\begin{array}{l}\text { Papanagiotou [29], } \\
2011\end{array}$ & $\begin{array}{l}\text { IV tPA, stent, penubra/ } \\
\text { stent retriever }\end{array}$ & 22 & TIMI 2/3 & 21 (95) & $\mathrm{mRS}$ score $0-2$ at $3 \mathrm{mo}$. & $9(41)$ & $3(14)$ & $4(18)$ \\
\hline $\begin{array}{l}\text { Ozdemir [38], } \\
2008\end{array}$ & IA tPA & 8 & TIMI $2 / 3$ & $6(75)$ & mRS score $0-2$ at 3 mo. & $8(100)$ & 0 & 0 \\
\hline $\begin{array}{l}\text { Zaidat }[4], \\
2002\end{array}$ & $\begin{array}{l}\text { IA tPA or UK, mechanical } \\
\text { thrombectomy }\end{array}$ & 18 & n.a. & n.a. & mRS score $0-2$ at $3 \mathrm{mo}$. & $6(33)$ & $9(50)$ & $3(17)$ \\
\hline Endo [3], 1998 & IA tPA or UK, angioplasty & 21 & successful & $8(38)$ & mRS score $0-2$ at $1 \mathrm{mo}$. & $5(24)$ & $10(48)$ & $1(5)$ \\
\hline
\end{tabular}

TIMI = Thrombolysis in myocardial infarction; UK = urokinase; $\mathrm{mo}=$ months; $\mathrm{n} . \mathrm{a} .=$ not available.

Paradoxically, the high rate of reperfusion did not correlate with the expected clinical outcome (mRS score 0-2; 41.3 vs. 53.0\% in ESCAPE, 60\% in SWIFT PRIME), and mortality was higher (18.9 vs. 9\%, 9\%) (table 2).

\section{Possible Factors Influencing the Outcomes of Stroke from Carotid Occlusion}

First, the clinical reality of ICA occlusion types is more complex. In the study by Fischer et al. [33], the classification of occlusion sites was divided into three groups: (a) ICA plus branch occlusion: ICA occlusion (extra- or intracranial) without occlusion of the main stem of the MCA (M1 or M2) or anterior cerebral artery (ACA; A1 or A2); (b) tandem occlusion: ICA occlusion (extra- or intracranial) combined with occlusion of either the MCA (M1 or M2) or ACA (A1 or A2), and (c) functional ICA T occlusion: extra- and/or intracranial occlusion of the ICA, extending into both the ACA A1 and MCA M1. It may exhibit huge clots and impaired collateral circulation. Furthermore, there is another occlusion type called pseudo-occlusion, which was defined as high-grade ICA stenosis with a severely reduced blood flow. Tandem occlusion involves the complexity of stroke mechanisms. Some cases are caused by a focal thrombus at the site of the intracranial occlusion. Others are caused by extracranial occlusions. Second, the underlying etiologies of ICA occlusion are too complicated to make an accurate judgment of the lesion pattern such as atherosclerosis, thromboembolic or artery dissection [34]. Third, the original size of the clots is usually larger in ICA than that of those ending up in the MCA. The clots that lodge in the ICA show greater stiffness compared to those that can pass farther to the MCA [16]. Fourth, the reason for a potentially increased risk of 
symptomatic intracranial hemorrhage ( $\mathrm{sICH}$ ) are (a) the flow dynamics and large infarction always present due to the large vessel occlusion, and (b) the antiplatelet medication used to prevent in-stent thrombosis, particularly following systemic thrombolysis [30]. The four points described above may challenge recanalization of the target artery. Outcomes are limited by long procedure times.

Optimal strategies of endovascular therapy for patients with acute ICA occlusion are still being elucidated. One of the most challenging technical steps is catheterization of the true lumen of the occluded ICA. Up to now, two different approaches (the antegrade and retrograde approaches), which vary in the order for the ICA stenting step, have been described in several studies. The antegrade approach (proximal ICA stenting followed by intracranial stent-based thrombectomy), which focuses first on the proximal occlusion, decreases the risk of distal embolization and reocclusion. However, it may delay cerebral reperfusion because of postponing the critical distal thrombectomy step. Cohen et al. [11] reported the largest case series on this endovascular method, with successful reperfusion (TICI $\geq 2 \mathrm{~b}$ ) achieved in $79 \%$ of the 24 patients and favorable outcome (mRS score $0-2$ ) achieved in $76 \%$. The retrograde approach (proximal balloon angioplasty, then intracranial stent-based thrombectomy followed by proximal ICA stenting), with direct access to the distal occlusion through the occluded cervical carotid, might have the primary advantage of reducing cerebral ischemic time in the territory [34]. The main concern is the risk of causing further injury to the carotid by devices moving, particularly if there is an unrecognized underlying dissection. The risk of reocclusion caused by untreated proximal carotid lesions even after initially successful mechanical thrombectomy should also be kept in mind. Cohen et al. [11] support the antegrade approach, as most acutely occlusive lesions of ICA represent atherosclerotic stenosis with impeded fresh soft thrombus being relatively easy to pass by microguidewire, limited resistance to preangioplasty, and should be used for a tightly meshed stent in order to adequately jail the friable plaque/clot. Gao et al. [35] also postulated that the restoration of proximal ICA flow would first augment antegrade perfusion pressure and collateral flow to facilitate intracranial recanalization. Nevertheless, either treatment may involve stent implement and require antiplatelet medication to prevent thrombosis. This approach may increase the risk of sICH, particularly following systemic thrombolysis.

Woodward et al. [36] reported a series of 7 patients with carotid stenosis of $65-100 \%$ and tandem MCA occlusions (table 2). They treated these cases with a novel modified Dotter technique, which is accomplished by crossing and dilating the ICA stenosis sequentially with a 6-Fr diagnostic catheter over a glidewire followed by advancement of a 6-Fr shuttle sheath across the stenosis. This technique may eliminate the need for immediate antiplatelet therapy, embolic protection devices, balloons and stents in most patients. It also facilitates short revascularization times, with an average time to TICI $2 \mathrm{~b}-3$ recanalization of $27 \mathrm{~min}$, which were achieved in all patients. The mean ICA stenosis was $88 \%$ before the procedure and $61 \%$ postoperatively. There were no cases with sICH. An mRS score of 0 was achieved in 6 of 7 (86\%) patients, and 1 patient died. These encouraging preliminary results need more confirmation from further experience and prospective randomized studies.

Some studies proposed that the primary cause of symptoms and outcome are mainly due to thrombus in the MCA other than ICA occlusion, because thrombus in the MCA may lead to occlusion of the orifices of the lenticulostriate arteries which are functional arteries without collateral [37]. Therefore, the condition of the lenticulostriate arteries and the recanalization time are critical for clinical outcome. Considering the time required, the risk of dissection and perforation by blind probing in an occluded vessel, dislodgement of thrombus and hyperperfusion syndrome for traversing the occluded cervical ICA to treat the MCA clot, Ozdemir et al. [38] reported 8 patients with tandem occlusion treated with microcathether navigation and 
IAT using collateral pathways including the anterior and/or posterior communicating arteries (table 2). The average time to thrombolysis in myocardial infarction 2-3 recanalization of 48 \pm 18 min was achieved in 6 out of $8(75 \%)$ patients. There were no complications caused by IAT through the collateral intact pathways. The favorable (mRS score $\leq 2$ or more) was achieved in all patients. However, the risk of dissection and embolization by advancing a microguidewire through the circle of Willis collaterals is a big concern. The absence of intact collateral pathways (PcomA and AcomA arteries) is the key for this technique. Hence, preprocedural evaluation of collateral pathways by computed tomographic angiography or magnetic resonance angiograhy may guide us to choose the most appropriate endovascular approach for patients.

Early reperfusion in a patient with a favorable penumbral pattern is also critical to achieve a favorable outcome in AIS. The early perfusion imaging-based analysis (including CT perfusion, MR perfusion or single-photon emission CT) might help to select optimal patients and classify the type of stroke mechanism as a focal or entire cause.

However, perfusion imaging-based analyses are not widely used at interventional stroke centers due to their limited facilities and the concern that the time to reperfusion will be extended [39].

\section{Conclusion}

Despite the complex classification of occlusion sites, different underlying etiologies, huge clot burden and high risk of sICH, endovascular treatment of acute ICA occlusion seems to be effective and safe. Intervention must be encouraged. Previous studies offer no final recommendations about the technical procedure, interventional stroke center remains challenging and tailor the treatment to individual patient needs. In a word, the best approach might depend on the type of vessel occlusion, and the time to treatment should be as short as possible.

\section{Acknowledgement}

The project is supported by the National Natural Science Foundation of China (NSFC, 81530038, 81571143).

\section{Disclosure Statement}

The authors have no conflicts of interest to disclose.

\section{References}

1 Rubiera M, Ribo M, Delgado-Mederos R, et al: Tandem internal carotid artery/middle cerebral artery occlusion: an independent predictor of poor outcome after systemic thrombolysis. Stroke 2006;37:2301-2305.

2 Meyer FB, Sundt TM Jr, Piepgras DG, et al: Emergency carotid endarterectomy for patients with acute carotid occlusion and profound neurological deficits. Ann Surg 1986;203:82-89.

3 Endo S, Kuwayama N, Hirashima Y, et al: Results of urgent thrombolysis in patients with major stroke and atherothrombotic occlusion of the cervical internal carotid artery. AJNR Am J Neuroradiol 1998;19:1169-1175.

4 Zaidat 00, Suarez JI, Santillan C, et al: Response to intra-arterial and combined intravenous and intra-arterial thrombolytic therapy in patients with distal internal carotid artery occlusion. Stroke 2002;33:1821-1826.

5 Goyal M, Demchuk AM, Menon BK, et al: Randomized assessment of rapid endovascular treatment of ischemic stroke. N Engl J Med 2015;372:1019-1030. 
6 Berkhemer OA, Fransen PS, Beumer D, et al: A randomized trial of intraarterial treatment for acute ischemic stroke. N Engl J Med 2015;372:11-20.

7 Saver JL, Goyal M, Bonafe A, et al: Stent-retriever thrombectomy after intravenous t-PA vs. t-PA alone in stroke. N Engl J Med.2015;372:2285-2295.

8 Campbell BC, Mitchell PJ, Kleinig TJ, et al: Endovascular therapy for ischemic stroke with perfusion-imaging selection. N Engl J Med 2015;12; 372:1009-1018.

9 Jovin TG, Chamorro A, Cobo E, et al: Thrombectomy within 8 hours after symptom onset in ischemic stroke. $\mathrm{N}$ Engl J Med 2015;372:2296-306.

10 Mpotsaris A, Bussmeyer M, Buchner $\mathrm{H}$, et al: Clinical outcome of neurointerventional emergency treatment of extra- or intracranial tandem occlusions in acute major stroke: antegrade approach with wallstent and solitaire stent retriever. Clin Neuroradiol 2013;23:207-215.

11 Cohen JE, Gomori JM, Rajz G, et al: Extracranial carotid artery stenting followed by intracranial stent-based thrombectomy for acute tandem occlusive disease. J Neurointerv Surg 2015;7:412-417.

12 Stampfl S, Ringleb PA, Mohlenbruch M, et al: Emergency cervical internal carotid artery stenting in combination with intracranial thrombectomy in acute stroke. Am J Neuroradiol 2014;35:741-746.

13 Mokin M, Kass-Hout T, Kass-Hout O, et al: Intravenous thrombolysis and endovascular therapy for acute ischemic stroke with internal carotid artery occlusion: a systematic review of clinical outcomes. Stroke 2012; 3:2362-2368.

14 Kappelhof M, Marquering HA, Berkhemer OA, et al: Intra-arterial treatment of patients with acute ischemic stroke and internal carotid artery occlusion: a literature review. J NeuroIntervent Surg 2015;7:8-15.

15 Mori E, Yoneda Y, Tabuchi M, et al: Intravenous recombinant tissue plasminogen activator in acute carotid artery territory stroke. Neurology 1992;42:976-982.

16 De Silva D. A, Brekenfeld dC, Ebinger M, et al: The benefits of intravenous thrombolysis relate to the site of baseline arterial occlusion in the Echoplanar Imaging Thrombolytic Evaluation Trial (EPITHET). Stroke 2010; 41:295-299.

17 Paciaroni M, Balucani C, Agnelli G, et al: Systemic thrombolysis in patients with acute ischemic stroke and internal carotid artery occlusion: the ICARO study. Stroke 2012;43:125-130.

18 Paciaroni, M, Agnelli G, Caso V, et al: Intravenous thrombolysis for acute ischemic stroke associated to extracranial internal carotid artery occlusion: the ICARO-2 study. Cerebrovasc Dis 2012;34:430-435.

19 Blinc A, Francis CW: Transport processes in fibrinolysis and fibrinolytic therapy. Thromb Haemost 1996;76: 481-491.

20 Rubiera M, Alvarez-Sabin J, Ribo M, et al: Predictors of early arterial reocclusion after tissue plasminogen activator-induced recanalization in acute ischemic stroke. Stroke 2005;36:1452-1456.

21 Molina CA, Montaner J, Arenillas JF, et al: Differential pattern of tissue plasminogen activator-induced proximal middle cerebral artery recanalization among stroke subtypes. Stroke 2004;35:486-490.

22 Saqqur M, Uchino K, Demchuk AM, et al: Site of arterial occlusion identified by transcranial Doppler predicts the response to intravenous thrombolysis for stroke. Stroke 2007;38:948-954.

23 Gao J, Dai Q, Liu X: Endovascular treatment for acute ischemic stroke: updates and future implications. Intervent Neurol 2015;4:43-47.

24 Palaniswami M, Yan B: Mechanical thrombectomy is now the Gold standard for acute ischemic stroke: implications for routine clinical practice. Intervent Neurol 2015;4:18-29.

25 Paciaroni M, Inzitari D, Agnelli G, et al: Intravenous thrombolysis or endovascular therapy for acute ischemic stroke associated with cervical internal carotid artery occlusion: the ICARO-3 study. J Neurol 2015;262:459468.

26 Saver JL, Jahan R, Levy EI, et al: Solitaire flow restoration device versus the MERCI retriever in patients with acute ischemic stroke (SWIFT): a randomized parallel-group, non-inferiority trial. Lancet 2012;380:12411249.

27 EI-Mitwalli A, Saad M, Christou I, et al: Clinical and sonographic patterns of tandem internal carotid artery/ middle cerebral artery occlusion in tissue plasminogen activator-treated patients. Stroke 2002;33:99-102.

28 Dababneh H, Guerrero WR, Khanna A, et al: Management of tandem occlusion stroke with endovascular therapy. Neurosurg Focus 2012;32:E16.

29 Papanagiotou P, Roth C, Walter S, et al: Carotid artery stenting in acute stroke. J AM Coll Cardiol 2011;23: 2362-2369.

30 Heck DV, Brown MD: Carotid stenting and intracranial thrombectomy for treatment of acute stroke due to tandem occlusions with aggressive antiplatelet therapy may be associated with a high incidence of intracranial hemorrhage. J Neurointerv Surg 2015;7:170-175.

31 Lockau H, Liebig T, Henning T, et al: Mechanical thrombectomy in tandem occlusion: procedural considerations and clinical results. Neuroradiology 2015;57:589-598.

32 Puri AS, Ku“hn AL, Kwon HJ, et al: Endovascular treatment of tandem vascular occlusions in acute ischemic stroke. J Neurointerv Surg 2015; 7:158-163.

33 Fischer U, Mono M.L, Schroth G, et al: Endovascular therapy in 201 patients with acute symptomatic occlusion of the internal carotid artery. Eur J Neurol 2013;20:1017-1024.

34 Lescher S, Czeppan K, Porto L, et al: Acute stroke and obstruction of the extracranial carotid artery combined with intracranial tandem occlusion: results of interventional revascularization. Cardiovasc Inervent Radiol 2015;38:304-313. 
Li et al.: Treatment Strategies for Acute Ischemic Stroke Caused by Carotid Artery Occlusion

35 Gao F, Joyce Lo W, Miao Z, et al: Combined use of stent angioplasty and mechanical thrombectomy for acute tandem internal carotid and middle cerebral artery occlusion. Neuroradiol J 2015;28:316-321.

36 Woodward K, Wegryn S, Staruk C, et al: The Dotter method revisited: early experience with a novel method of rapid internal carotid artery revascularization in the setting of acute ischemic stroke. J Neurointerv Surg 2016; 8:360-366.

37 Donnan G, Norrving B, Bamford J, et al: Striocapsular Infarcts. Oxford, Oxford University Press, 2002, pp 195-208.

38 Ozdemir 0, Bussiere M, Leung A, et al: Intra-arterial thrombolysis of occluded middle cerebral artery by use of collateral pathways in patients with tandem cervical carotid artery/middle cerebral artery occlusion. AJNR AmJ Neuroradiol 2008;29:1596-1600.

39 Donnan GA, Davis SM: Neuroimaging, the ischaemic penumbra, and selection of patients for acute stroke therapy. Lancet Neurol 2002;1:417-425. 